\title{
Mineração e entropia: notas sobre interação com processos de desenvolvimento
}

Maurílio de Abreu Monteiro - Professor e pesquisador do Núcleo de Altos Estudos Amazônicos da Universidade Federal do Pará - NAEA/UFPA.

Maria Célia Nunes Coelho - Professora do Programa de Pós-graduação em Geografia da Universidade Federal do Rio de Janeiro.

\section{Resumo}

O artigo apresenta pressupostos teóricos e metodológicos relevantes para a interpretação das interações estabelecidas entre mineração e desenvolvimento regional. É refutada a hipótese de que os mecanismos de mercado afastam a irreversibilidade dos processos entrópicos, como defende a economia dos recursos naturais de inspiração neoclássica. Refuta-se também a noção de que a degradação entrópica, do ponto de vista social, é, inexoravelmente, negativa, como pressupõe a economia ecológica. Como alternativa analítica, indicam-se abordagens que interpretam a sociedade capitalista como um sistema longe do equilíbrio e sustenta-se que as repercussões sociais da degradação entrópica decorrente da mineração vinculam-se ao modo de interação entre competências técnicas, características históricas, sociais, culturais, políticas e especialidades e potencialidades naturais de uma determinada formação social.

\section{Abstract}

This article presents theoretical and methodological assumptions that are relevant for the interpretation of the interactions between mining and regional development. It refutes the hypothesis of market mechanisms driving away the irreversibility of entropic processes, defended by the natural resources economy of neoclassical inspiration. The notion that the entropic degradation, from a social point of view, is inexorably negative - as proposed by the ecologic economy - is also refuted. Approaches of interpretation of the capitalist society as a system far away from balance are indicated as analytical alternatives. The author proposes that social repercussions of entropic degradation resulting from mining activities are connected to the interaction model between technical competence, historical, social, cultural and political features, and natural specialties and potentialities of a given social formation.

\section{Palavras-chave}

Mineração, entropia, desenvolvimento regional.

\section{Keywords}

Mining, entropy, regional development.

* A elaboração deste artigo contou com a colaboração do CNPq. 


\section{INTRODUÇÃO}

O caráter multifacetado e acelerado das transformações sociais tem trazido sérias dificuldades aos analistas que buscam interpretar os padrões identificáveis nos aparentemente desconexos e contraditórios processos sociais, econômicos, políticos, culturais e mesmo físico-ambientais. Muitos cientistas sociais têm decidido anunciar, não sem boas justificativas, a ausência de padrões. Ou, em outras palavras, a impossibilidade de se identificar um quadro coerente e consistente de dinâmicas e estruturas, simplesmente porque não existiria tal coerência e consistência.

A questão, no entanto, pode ser colocada (e tratada) de uma outra maneira. O esforço pode residir na tentativa de se abordar uma realidade que é reconhecidamente complexa a partir de perspectivas que identificam estruturas e determinações. A uma realidade multifacetada, responde-se normalmente com perspectivas teóricas e metodológicas que simplificam os fenômenos a tal nível que deles não se apreendem o que é fundamental.

As dimensões socioeconômica e ambiental, mesmo que entrelaçadas temporal e espacialmente, possuem ritmos e lógicas diferenciadas. Tal constatação não pode levar, no entanto, a se abrir mão de uma reflexão integrada da realidade, na qual é possível identificar algumas dinâmicas ou padrões estruturantes que ensejam a existência de sistemas dotados de sujeitos e determinações, mas nem por isto são sistemas previsíveis. É com base nessa percepção da realidade que se busca neste artigo avançar na construção de uma abordagem teórica e metodológica para se analisar a mineração industrial e sua relação com processos de desenvolvimento.

\section{Perspectivas teórico-metodológicas}

A partir de uma revisão crítica de várias perspectivas teóricometodológicas destinadas a analisar a valorização de recursos naturais e os impactos sociais e ambientais dessa mercantilização, apresentamse, inicialmente, três orientações teóricas que captam apenas a aparência das manifestações fenomênicas sem constituírem instrumentos heurísticos que permitem apreender a essência dos fenômenos relacionados à mineração e a sua relação com processos de desenvolvimento, sendo por isto refutadas; em seguida, quatro posições teóricas são abordadas no intuito de fixar fundamentos analíticos mais adequados ao tratamento do problema.

\subsection{Supostos teórico-metodológicos refutáveis}

Três premissas teóricas que são objeto de refutação. A primeira está relacionada ao futuro das economias ricas em matérias-primas na economia planetária, a propósito da discussão sobre a tese da crescente "desmaterialização" da economia mundial. A segunda diz respeito ao debate 
teórico sobre a regulação por mecanismos do mercado, que seriam os mais eficazes para interpretar os fundamentos da utilização dos recursos minerais e a sua integração com processos de desenvolvimento. Por fim, refuta-se o suposto de que o aumento de entropia, necessariamente, tem efeito negativo sobre processos de desenvolvimento social.

\subsubsection{A "desmaterialização" da produção industrial moderna}

A primeira premissa teórica refutada fundamenta-se na hipótese de que, na economia moderna, a redução dos custos de produção, no que se refere aos custos tanto da força de trabalho quanto dos insumos, tem feito decrescer, historicamente, o volume de matéria e de energia alocadas na reprodução da sociedade moderna.

Se é verdade que houve um processo generalizado de redução de inputs materiais por unidade de mercadoria produzida (GONZALEZVIGIL, 1984), não se pode deduzir, automaticamente, que a essa redução correspondeu uma retração dos fluxos de matéria-prima no comércio mundial, especialmente dos minérios. No caso da indústria automobilística, a diminuição da quantidade de matéria-prima utilizada na produção de um automóvel foi acompanhada pela ampliação do volume total de carros produzidos no planeta (SCHIPPER, 1997). As reduções materiais em termos unitários estão, portanto, associadas ao crescimento da produção mercantil e, como conseqüência, à tendência de demandas ainda maiores de matéria nos processos industriais.

Apesar da redução, durante o século XX, da intensidade energético-material da valorização mercantil - expressa pela razão entre a demanda energética e os preços das mercadorias -, houve, simultaneamente, o aumento da demanda mundial de energia e matéria (MARTIN, 1992; NAKICENOVIC, 1997; FEMIA, 1996). Assim, a economia moderna recorre a montantes crescentes de matéria e energia, transportadas por distâncias cada vez maiores (BUNKER, 1996) e utilizadas em taxas superiores às taxas em que foram acumuladas.

Para suprir tais demandas, há necessidade de se ter acesso a grandes concentrações minerais até então não integradas ao processo produtivo. As escalas industriais de produção e transporte passaram a requerer também que as jazidas, para terem viabilidade econômica, tivessem dimensões cada vez maiores. A extração mineral tem ocorrido em áreas mais remotas em relação ao seu local de demanda, tanto por causa da expansão da demanda global quanto pelo esgotamento de reservas mais acessíveis (BARHAM; BUNKER; O'HEARN, 1994).

Contrariando aqueles que visualizam uma tendência de "desmaterialização" na economia moderna (TIBBS, 1992), deve-se ressaltar o papel fundamental dos fluxos materiais e energéticos na economia globalizada e o papel relevante das estruturas sociais e econômicas presentes em economias "dominantemente extrativas" (BUNKER, 1985) no fornecimento de matérias-primas a "economias centrais". Persiste, no 
contexto de uma estrutura mundial hierarquizada, o favorecimento às últimas; e grandes dificuldades, para o estabelecimento do crescimento de estruturas produtivas que tendem a se complexificar o que dificulta a afirmação de processos de desenvolvimento nas primeiras.

\subsubsection{A irreversibilidade entrópica é afastada pelos mecanismos de mercado}

A segunda premissa teórica que se refuta procura explicar a utilização de recursos minerais, bem como a posterior deposição dos rejeitos resultantes da exploração e do uso desses recursos, como dinâmicas derivadas da busca de alocação ótima, via mercado, dos chamados "fatores de produção" (capital, trabalho e, em certos casos, terra) pelos agentes econômicos em termos individuais. Partindo do pressuposto de que a partir das lógicas de mercado é possível internalizar externalidades negativas (degradação ambiental, poluição, etc.), vistas como falhas de mercado, os autores ligados a essa corrente acreditam que: a) recursos minerais podem ser substituídos por outros recursos em função de sinalizações fornecidas pelo mercado; b) a irreversibilidade dos processos de degradação entrópica é afastada pela existência de uma "inteligência sistêmica" derivada de mecanismos de mercado; c) análises de custos marginais guiam as ações dos agentes sociais; d) o mercado atua como alocador ótimo dos "fatores de produção" em termos sociais.

Desses supostos teóricos derivaram duas proposições analíticas de tratamento da problemática relacionada à utilização dos recursos minerais e à degradação ambiental, vinculadas à economia de recursos naturais e à economia do meio ambiente, ambas de fundamentação neoclássica. A primeira delas enfatiza que o comportamento dos agentes pode ser entendido e analisado como função da ação individual na busca da melhor alocação dos fatores de produção, enquanto a segunda procura formular indicações para que se alcance "um nível ótimo de poluição", que seria atingido por meio das preferências dos indivíduos, expressas pelo mercado. As duas abordagens supõem a possibilidade de mensurar monetariamente e internalizar as "externalidades" tidas como fenômenos que ocorreriam ainda à margem da formação dos preços. Esse processo de "precificação" pode dar-se, entre outros mecanismos, pela definição clara dos direitos de propriedade, que implicaria a negociação direta de direitos pelo agente que degrada e pelo que é afetado pela degradação - abordagem influenciada pelo trabalho pioneiro de Coase (1988) -, ou pelo arbitramento dos custos da degradação ambiental, taxando os degradadores - posição derivada das formulações de Pigou (1932).

No âmbito da economia de recursos naturais, as formulações acerca da extração de recursos minerais derivam, na sua ampla maioria, do trabalho de Hotelling (1932), que, dada a esgotabilidade do recurso 
mineral, estabelece uma proposição para tratar do estabelecimento da via e do tempo ótimo de exaustão desses recursos, em função das indicações fornecidas pelos preços.

Essas visões teóricas partem do pressuposto de que, havendo a internalização das externalidades negativas decorrentes da exploração mineral, tanto a região na qual ocorre a extração quanto aquela na qual há sua industrialização, tal atividade colaboraria para impulsionar processos de desenvolvimento na região porventura menos desenvolvida. Com efeito, na visão dos atores adeptos dessas correntes, a ampliação do comércio beneficia todos os nele envolvidos, desde que as transações respeitem o "livre comércio" e as "vantagens comparativas na alocação dos fatores de produção" que cada região possua. As formações econômicas e sociais tenderiam, portanto, a avançar para um equilíbrio em termos de desenvolvimento, quer se exportassem, quer se importassem bens de origem mineral, matérias-primas ou produtos elaborados.

\subsubsection{A degradação entrópica é inexoravelmente negativa}

As abordagens analíticas de caráter neoclássico, apontadas no item anterior, têm como fonte de inspiração teórico-metodológica o modelo derivado da mecânica clássica ligada à física newtoniana. Operam com um esquema analítico que as conduz a indicar que as relações estabelecidas por intermédio da compra e venda de mercadorias tendem ao equilíbrio e que as forças de mercado atuando livremente seriam as que melhor alocariam os recursos da sociedade, permitindo, assim, a mais racional e eficaz utilização dos recursos minerais e o igual desenvolvimento das áreas nas quais se extraem e se industrializam tais produtos. Todavia, é possível indicar uma outra corrente que se baseia em outro suposto teórico: o da irreversibilidade entrópica.

São proposições analíticas que, inspirando-se em modelos derivados da termodinâmica clássica, pressupõem, diferentemente dos esquemas neoclássicos, a irreversibilidade dos processos produtivos, pois a degradação entrópica, tanto energética quanto material, seria irreversível. A partir dos anos 70, surgem diversos trabalhos derivados da aplicação da noção de degradação à produção social. Desses trabalhos, o mais expressivo é o de Georgescu-Roegen (1971), que considera a produção um processo de dissipação de matéria e energia e chama a atenção para o fato de que cada transformação da matéria e da energia resulta em um aumento irreversível da entropia. Dessa forma, em decorrência do processo de produção, há alterações de ordem não apenas quantitativa, mas também qualitativa, já que matéria e energia entram no processo produtivo em um estado de baixa entropia e saem em um estado de alta entropia, fazendo com que o processo econômico tenha uma evolução unidirecional irrevogável (GEORGESCUROEGEN, 1989). Nos processos produtivos, portanto, dever-se-ia 
considerar em termos analíticos a dissipação energética e a dispersão material (GEORGESCU-ROEGEN, 1971). Ao dissipar matéria e energia, os processos produtivos geram rejeitos, reduzem a quantidade de energia disponível para realizar trabalho útil e os estoques de matéria socialmente aproveitáveis (Figura 1).

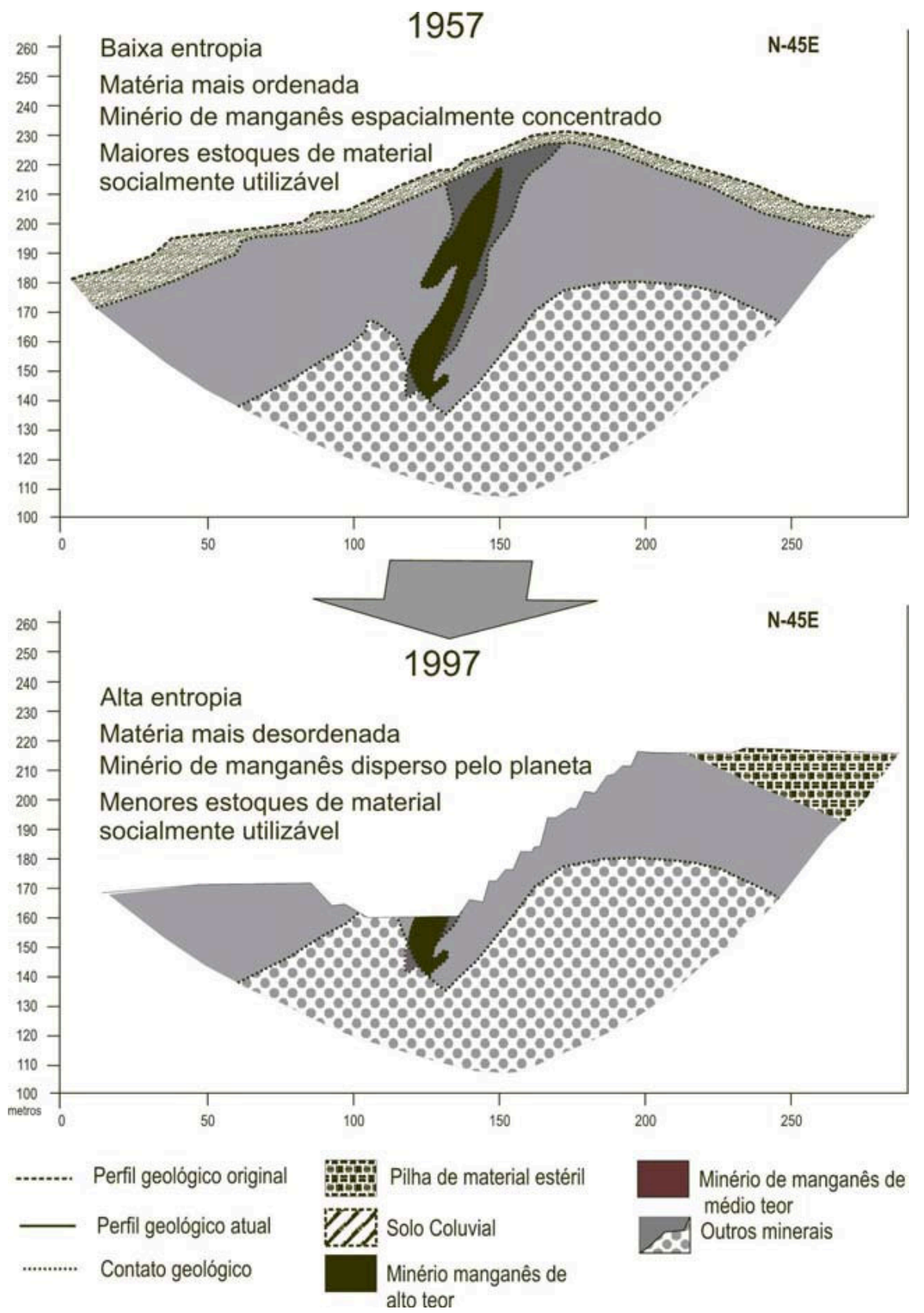

Figura 1: Representação esquemática de implicações entrópicas da valorização da mina de manganês T11, Serra do Navio, Amapá, Brasil.

Fonte: Elaboração dos autores baseada em Monteiro (2002).

28 
Com base na convicção teórica de que a degradação entrópica tem repercussões diretas nos processos de organização e desenvolvimento das sociedades, diversos autores passam a sugerir formulações que buscam incorporar aos esquemas analíticos os efeitos da ampliação da entropia na sociedade.

Os autores que mais radicalizam essa perspectiva sugerem uma unidade para mensurar a degradação dos estoques energético-materiais planetários. Para eles, as trocas realizadas na sociedade para representar sua expressão energética material deveriam indicar a memória da quantidade de energia solar requerida pela produção de um determinado objeto. Assim, Odum (1995) sugere como medida para tanto a emergy, unidade que representaria a memória de energia solar necessária, por exemplo, para concentrar na crosta terrestre uma tonelada de minério de ferro e indicaria a magnitude da dispersão energético-material derivada da explotação do volume desse minério.

Inspirado no trabalho de Georgescu-Roegen, Daly (1989b) desenvolve um conjunto de proposições conhecidas como a "economia em estado estacionário". Os seguidores dessa abordagem defendem a necessidade do estabelecimento de rigorosos mecanismos institucionais de controle para se manter constante o "capital natural", como licenças para nascimentos; para esgotamento de recursos naturais, entre os quais os recursos minerais; e para emissões de rejeitos e poluentes (DALY, 1989a, 1989b). Para Daly, a utilização socialmente mais adequada dos recursos minerais e de emissões prejudiciais ao ambiente seria regulada por licenças cuja lógica não estaria submetida ao mercado, mas seria estabelecida politicamente.

Entre as abordagens ligadas ao suposto teórico da degradação entrópica, é possível encontrar também formulações que estão no extremo desse campo e não radicalizam como Odum (1995) os desdobramentos desse suposto. É o caso da abordagem marcada pelas análises de balanços de matéria e energia, voltada, sobretudo, para a produção de estudos que têm como foco a indicação de possíveis mecanismos de redução da taxa de degradação entrópica de processos produtivos, no geral, tratados individualmente. Os trabalhos de Ayres e Kneese (1969) e os de Mäler (1974) são representativos desse tipo de abordagem. Os inúmeros estudos inspirados nessa abordagem enfatizam a otimização de processos produtivos do ponto de vista de sua eficiência energética e material. Tais estudos costumeiramente são agrupados sob a denominação de ecologia industrial.

Também apoiado na noção de negatividade social da degradação entrópica e na necessidade de manter constante o "capital natural", foi desenvolvido, a partir do London Environmental Economics Centre, um conjunto de formulações que se convencionou denominar "Escola de Londres". Pearce, Barbier e Markandya (1991), entre outros, destacam a existência de barreiras ambientais absolutas nos processos de 
desenvolvimento; por isso, preconizam o estabelecimento de mecanismos de criação de preços artificiais para favorecer a manutenção dos estoques globais de capital natural.

Entretanto, a "Escola de Londres" não desenvolveu instrumentos inovadores de avaliação das barreiras ambientais impostas ao processo produtivo e, para tanto, recorre a instrumentos tradicionais vinculados à "precificação" de preferências individuais para, a partir delas, estabelecer políticas que viabilizem a manutenção do capital natural constante. A opção por técnicas de avaliação e valoração dos impactos decorrentes da ação antrópica, baseadas em preferências individuais, não representa avanços significativos em termos metodológicos, fragilizando a capacidade de captar analiticamente a relação entre sociedade e natureza e, sobretudo, entre degradação energéticomaterial e processos de desenvolvimento.

\subsection{Indicações analíticas para relacionar a exploração de recursos minerais com o desenvolvimento}

Além da superficialidade explicativa das noções de equilíbrio e da inexorável negatividade decorrente da degradação entrópica, é preciso considerar a diversidade das dinâmicas sociais e ecológicas associadas à utilização de recursos minerais demandados pela economia global quando se busca uma abordagem integrada dos contextos regionais e dos processos de desenvolvimento.

Na bibliografia sobre desenvolvimento, tem destaque a análise das conseqüências, para os países e as regiões produtoras, da exportação de matérias-primas para os países e as regiões mais industrializadas. Desenvolvimento e seu par subdesenvolvimento são muitas vezes equivocadamente indicados como estágios de avanço das forças produtivas por meio da acumulação e da reprodução do capital ao longo das vias alternativas do capitalismo ou do socialismo (CHILCOTE, 1998, p. 284). O desenvolvimento é também usualmente associado à modernização fundamentada na industrialização, no crescimento econômico, na acumulação e na difusão do capital e da tecnologia.

A superação das teorias que ignoram as desigualdades estruturais entre países e regiões pode auxiliar na compreensão das relações entre o desenvolvimento e a grande mineração nas regiões ou países periféricos. Nesse sentido procuram-se abordagens das implicações da valorização de recursos minerais que incorporem a análise das dinâmicas causadoras de hierarquizações entre regiões e países e também abordagens que investiguem os impactos das grandes mineradoras nas regiões em que estão localizadas.

Quatro indicações fornecem os elementos necessários para dar sustentação analítica a essa perspectiva: a primeira relaciona-se às diferentes correntes da economia política dos recursos naturais; a segunda, às abordagens das teorias de desenvolvimento e 
subdesenvolvimento; a terceira enfatiza a análise da economia política marxista; a quarta trata das contribuições da análise dos sistemas complexos longe do equilíbrio para a análise proposta.

\subsubsection{A economia política dos recursos naturais}

O primeiro caminho diz respeito à análise dos recursos naturais não renováveis e da degradação entrópica resultante dessa exploração em um quadro mais amplo das relações entre sociedade e natureza.

Uma forma de análise das implicações da valorização de recursos minerais para os processos de desenvolvimento é a da economia política de inspiração marxista, que faz uma interpretação histórica e evolutiva das relações entre sociedade e natureza. A análise dialética dessas relações considera a natureza permanentemente transformada pela sociedade e influenciadora de novas transformações (HARVEY, 1996). Aborda, portanto, as mudanças ambientais e sociais, bem como as transformações políticas, econômicas, espaciais e culturais relacionadas com a utilização dos recursos extraídos da natureza.

Nesse contexto, recursos naturais são a classe de bens não produtíveis pelos seres humanos. Recursos naturais são todos os elementos da natureza (minerais, biológicos) para os quais existe utilidade (necessidade real ou artificialmente criada), conhecimento científico e tecnologia economicamente viável que justifiquem sua exploração.

Ao ser valorizado - entendendo-se valorização como a incorporação de valor pelo trabalho humano -, o recurso mineral, por adquirir valor de uso e valor de troca, constitui-se em uma mercadoria, assumindo a forma elementar mais geral presente na sociedade capitalista: por exemplo, os minerais presentes em uma determinada jazida, mercantilizados por meio da incorporação de trabalho, transformam-se em mercadoria. Na natureza, o recurso natural não depende de trabalho para possuir, intrinsecamente, qualidades úteis. Todavia, o valor de troca revela-se, "na relação quantitativa entre valores-de-uso de espécies diferente, na proporção em que se trocam, relações que mudam constantemente no tempo e no espaço" (MARX, 1989, p. 58). A tecnologia amplia a quantidade, a utilidade (por meio de processamento industrial) e o acesso aos recursos naturais enquanto mercadorias. Recurso natural é assim um conceito econômico, historicamente determinado pelas necessidades sociais e pelo avanço da ciência e da tecnologia.

A economia política, de inspiração marxista, considera, particularmente, as relações entre política, economia, sociedade e cultura, que têm como produto uma formação social específica. Tais formulações pretendem incorporar a dimensão ambiental e as dinâmicas espaciais. Foi o que tentaram diferentes autores, como Soja (1993), Redclift (1984), Barham, Bunker e O’Hearn (1994), Harvey (1996) e Bunker (1996).

A dimensão ambiental é regulada por determinações do mundo biofísico, que não deixam de interferir nas determinações sociais, pois 
a localização geográfica e as propriedades biofísicas dos recursos naturais influenciam diretamente as formas de operacionalização e de organização da produção (BUNKER, 1996); a dimensão socioeconômica dispõe sobre a valoração dos produtos e a produção de excedentes econômicos e diz respeito também ao papel e às estratégias do Estado, dos grupos e classes sociais que geram as decisões estimuladoras e reguladoras de desenvolvimento. A dimensão socioeconômica deve levar em conta as dinâmicas a distribuição espacial dos ganhos oriundos da valorização de recursos minerais depende da forma como as classes sociais e a economia se estruturam numa região em processos de valorização do valor (HARVEY, 1996).

As relações entre as dimensões socioeconômica e ambiental encerram determinações sociais que estabelecem possibilidades e limites para as dinâmicas de desenvolvimento derivadas da exportação de recursos naturais em certas formações sociais. Reconhece-se, portanto, a especificidade das formações sociais, e busca-se explicar variações estruturais dentro delas (REDCLIFT, 1984). Nesse sentido, a economia política posiciona cada formação social, cada região e cada classe social no contexto de uma economia-mundo, e os efeitos que isso lhes acarreta em termos de exploração dos recursos naturais (YAPA, 1980; REDCLIFT, 1984, 1987). Procura-se investigar o processo de intensificação da extração e transformação dos recursos naturais em todo o mundo, a partir da análise dos impactos diferenciados produzidos sobre as classes sociais, o ambiente natural, o espaço, as formações sociais e a "economia-mundo".

\subsubsection{Economia política e teorização sobre o subdesenvolvimento}

Nas décadas de 60 e 70, destacam-se as contribuições de Frank (1966) e Samir Amin (1974) sobre a inserção da América Latina no sistema mundial hierarquizado, a formulação da noção de "causação circular cumulativa" (MYRDAL, 1957) e a concepção do desenvolvimento como uma cadeia de desequilíbrios (HIRSCHMAN, 1961). Além disso, os estudos dos teóricos da dependência, como Rui Mauro Marini (1969), Teotônio dos Santos (1978), Cardoso e Faletto (1979), foram importantes para a teorização sobre os efeitos das exportações de matérias-primas nos processos de subdesenvolvimento dos países ou regiões periféricas ricas em minerais, a partir da explicitação da hierarquização e dos fundamentos políticos e econômicos no sistema mundial. Essa hierarquização tinha, em termos de desenvolvimento, efeitos diferenciados dos impactos do comércio de produtos de origem mineral nas diversas formações sociais.

À teoria da economia-mundo, influenciada pelos trabalhos de Wallerstein (1974) e Arghiri (1972), acrescentaram-se as análises baseadas nas trocas energéticas desiguais, realizadas Bunker (1985) e Altvater (1995), inspirados na noção de degradação entrópica, 
argumentam que o fluxo de matéria e energia de uma região para as outras reduz a complexidade e faz crescer a entropia na região de origem, enquanto aumenta a complexidade e o poder da região de destino.

Na visão dos autores um modelo adequado de interação entre economia global e diferentes formações sociais tem o dever de incorporar, nos esquemas analíticos, as diferenças e a interdependência entre elas. Wallerstein (1974), Arguiri (1972) e Bunker (1996) chamam a atenção para a dificuldade de inserir o local no global e para a ausência de análises interescalares que enfatizem as mudanças na estruturação do sistema mundial e as alterações nas lógicas de subordinação das nações periféricas ricas em matérias-primas aos países centrais. Nesses termos, compreender a singularidade dos processos locais requer a explicitação das determinações de diversos níveis nos processos de desenvolvimento, entre elas as de caráter planetário.

\subsubsection{Economia política e a noção de enclave}

Um ponto importante da análise das relações estabelecidas entre mineração e desenvolvimento diz respeito ao caráter de enclave comumente atribuído a atividades mineiras de grande porte (COELHO, 2000). Essas atividades formariam economias separadas das economias locais. Representariam assim um território separado de um domínio e contido em outro. Os enclaves econômicos seriam, portanto, núcleos de atividades primárias controladas de forma direta pelo exterior, ou uma jurisdição, ou uma economia (moderna) separada da economia local (atrasada) e compreendida em outra.

Cardoso e Faletto (1970) distinguem dois tipos de enclaves: o agrícola e o mineiro. O enclave mineiro caracteriza-se pela reduzida capacidade de absorção de mão-de-obra e pela elevada concentração de capital.

As análises dos enclaves no contexto da teoria da dependência (CARDOSO, FALETTO, 1970) permitiram uma visão crítica dos efeitos da modernização nas estruturas tradicionais. Todavia, é necessário superar os estudos que não dão a importância devida aos efeitos dos supostos enclaves na reestruturação social e econômica de diversas formações sociais, mesmo que os efeitos de encadeamento para frente e para trás sejam reduzidos ou nulos. Não satisfaz a constatação de que conexões fortes com a economia local não são estabelecidas. É preciso explicar o que acontece nas áreas de influência da mineração.

Ao contrário das expectativas dos teóricos que abordam atividades voltadas para a valorização de recursos minerais destinados à exportação como enclaves, a atividade mineral atua como elemento (re)estruturante de atividades produtivas ao mudar ou reforçar lógicas preexistentes na economia regional. As redes de transportes, comunicações e energia são expandidas, criando-se novas possibilidades de desenvolvimento e de incorporação das atividades agrícolas e pecuárias à economia 
regional. Em pontos nodais (nódulos de redes), cresce a possibilidade de emergência de uma economia urbano-industrial.

Com o povoamento acompanhado da intensificação do processo de urbanização, as novas cidades concentram, contraditoriamente, os migrantes atraídos pela atividade mineira e dela excluídos. O conflito entre as mineradoras e os diversos segmentos sociais que pressionam pela elevação local da renda tende a ser contínuo.

O tratamento teórico da grande mineração industrial como enclave leva à compreensão da atividade como algo isolado, ou seja, como uma estrutura separada, e não como parte de um processo de transformação territorialmente mais amplo.

\subsubsection{A noção de sistemas longe do equilíbrio}

Diferentemente das formulações teóricas inspiradas na noção de equilíbrio e das derivadas do suposto da inexorável negatividade, em termos sociais, da ampliação da entropia energético material, anteriormente apontadas como ineficazes para fornecer instrumental analítico para se interpretar as relações entre mineração e desenvolvimento, algumas correntes teóricas inspiradas nos fundamentos epistemológicos dos trabalhos de Prigogine e Stengers (1984) representam caminhos heurísticos mais apropriados. Essas abordagens incorporam ao seu esquema analítico princípios das teorias dos sistemas abertos, da informação, da organização e da evolução, o que permite construir argumentações mais otimistas em relação aos processos que envolvem a crescente ampliação da entropia e suas repercussões sobre a estruturação social, uma vez que se busca apresentar uma interação dialética entre a degradação entrópica e a criação evolutiva.

Prigogine e Stengers (1984) afirmam que a crescente ampliação da entropia pode desempenhar um papel construtivo e significar estágios, momentos de um processo de evolução. Mais do que isso, deve ser vista como uma condição para a evolução dos sistemas (PRIGOGINE, 1996). A ampliação da entropia (como, por exemplo, a exaustão de uma mina) pode contribuir para a gestação de uma formação social mais resiliente. Essa corrente enfatiza noções como as de sistemas auto-organizados, sistemas complexos, estruturas dissipativas, evolução, processos internos do sistema e inovação, que podem ajudar a interpretar desdobramentos de dinâmicas sociais. Entre as principais abordagens, pode-se citar a economia evolucionária, que engloba os estudos de padrão de inovação tecnológica e os de conservação de padrões de operação. Trata-se de investigar, por exemplo, como as características de patterns (empresas) são reproduzidas, mesmo estando submetidas à pressão seletiva. Nesse campo, há trabalhos mais gerais, como os de Nelson e Winter (1982), e os que servem como referência para a transformação técnica, como os de Dosi et al (1988) e Freeman 
(1994). O que teria relevância explicativa para a compreensão de processos de desenvolvimento de regiões cuja economia é baseada na exportação dos recursos naturais seriam as relações sociais estabelecidas para a valorização desses recursos, e não somente o conteúdo das exportações.

\section{Outras contribuições ao debate proposto}

Os historiadores, com sua visão de longa e curta duração, os geógrafos, com seus estudos dos processos de organização espacial, e os sociólogos que se dedicam ao exame da sociedade diferenciada em classes podem unir-se para indicar determinações nas relações sociais, espaciais, históricas e ecológicas em formações sociais periféricas e ricas em matérias-primas. As relações mantidas entre classes, as desenvolvidas entre formações sociais, as suas variações no tempo e no espaço acham-se representadas sob a forma de desigualdades socioespaciais, cuja análise é necessária. É preciso, portanto, identificar totalidades dotadas de algum tipo de determinação sistêmica ou estrutural e suas repercussões nas organizações territoriais, em contextos locais, regionais, nas formações econômicas e sociais. Tampouco se deve esquecer que a análise das determinações sistêmicas requer uma visão de longo prazo da evolução de uma dada sociedade (BRAUDEL, 1982; HOBSBAWM, 1998).

A teoria dos sistemas complexos, não lineares, longe do equilíbrio pode fazer evoluir a investigação sobre os processos estruturantes do espaço, desencadeados pela valorização de recursos minerais. Tal teoria oferece uma possibilidade de interpretação mais coerente dos sistemas sociais e físico-ambientais, graças à noção de auto-organização. Tratase de admitir que um sistema, uma totalidade conta com determinações, mas não o torna previsível. Não há equilíbrio, há estado de relativa estabilidade, que é temporal.

$\mathrm{Na}$ abordagem teórica dos sistemas dinâmicos longe do equilíbrio (PRIGOGINE; STENGERS, 1992), a estrutura é vista como um atrator na trajetória do sistema. Um atrator é o ponto para o qual convergem as trajetórias do sistema. Em outras palavras, corresponde a uma estrutura que determina a direção (ou o comportamento temporal) de acordo com a qual o sistema se movimenta (PRIGOGINE; STENGERS, 1992).

O aparecimento de novos elementos estruturantes, de força comparável a de um atrator, pode mudar as trajetórias regionais. Da mesma forma, uma atividade econômica ou a infra-estrutura a ela associada pode, em certa medida, funcionar como uma força motriz para a acumulação de capital e como fonte de reestruturação de formações sociais, e não apenas como um elemento perturbador de uma dada ordem. Trata-se de descobrir em que medida ou em que condições a exploração ou a infra-estrutura associada à mineração tornam-se "forças estruturantes" para uma a região. 


\subsection{Propriedades das minas e repercussões nas trajetórias das formações sociais}

A análise das trajetórias de formações sociais a partir de sua alteração pela introdução da grande mineração industrial não pode prescindir do exame da distribuição geográfica, das propriedades físicoquímicas dos recursos naturais e do quadro natural, pois são elementos que interferem diretamente na valorização dos recursos minerais e influem nos processos de desenvolvimento.

Segundo Innis (1956) e Bunker (1985), a incorporação dos atributos físicos e espaciais dos recursos valorizados às análises é fundamental para a elucidação de trajetórias sociais, econômicas, financeiras e políticas da região. Isso se explica pelo fato de que as características da matéria-prima influem, simultaneamente, na forma, na intensidade e na organização do trabalho. Barham, Bunker e O'Hearn (1994) analisam como propriedades físicas a localização espacial e a topografia das áreas de ocorrência dos recursos naturais, que influenciam a organização e a operação das indústrias voltadas para a valorização de recursos minerais.

Para Bunker (1994b), a crescente escala e as localizações remotas da extração mineral, como no caso da Amazônia, causaram sérias rupturas nas economias e instituições regionais e disputas de classe. Tais rupturas decorrem da modernização da infra-estrutura de extração, transporte e processamento, de um lado, e da forte migração para as áreas mineradoras, de outro. Alterou-se o ambiente físico e limitou-se a expansão de dinâmicas preestabelecidas ou em fase de implantação.

Assim, há de se considerar nos esquemas analíticos que processos que viabilizam a valorização de recursos minerais em larga escala e as infra-estruturas associadas estão ligados às propriedades das minas que, por vezes, condicionam o estabelecimento de diferenciadas dinâmicas de organização da produção mercantil com repercussões sociais variadas.

\subsection{Recursos naturais e organização territorial}

Para abordar as questões da organização do território e do desenvolvimento regional, recorre-se, comumente, aos trabalhos de Albert Weber (1957). Suas formulações servem de inspiração analítica para os que trabalham com as noções de equilíbrio e de preços estabelecidos em decorrência da concorrência perfeita. Assim, para justificar a localização e a aglomeração de atividades econômicas, entre as quais a mineração, a metalurgia e a siderurgia, a geografia econômica weberiana apóia-se nos fundamentos teóricos da economia neoclássica. A existência e a localização de determinada atividade devem-se a dinâmicas de formação de preços pela oferta e demanda da mercadoria. A relação entre atividade produtiva e processos de desenvolvimento baseia-se no ganho comum dos envolvidos no comércio, em função da utilização da vantagem comparativa na alocação dos fatores de produção.

A empiria tem demonstrado a artificialidade da formulação teórica 
das "vantagens comparativas" do comércio internacional. No caso do comércio mundial de mercadorias de origem mineral, é mais evidente que não tem resultado em vantagem para todas as partes envolvidas no comércio (BENKO, 1996).

No que se refere ao padrão de localização, as atividades envolvidas na primeira etapa da valorização de minerais possuem uma rigidez locacional, não podendo, portanto, beneficiar-se de uma série de vantagens das aglomerações já existentes no momento em que tais recursos serão convertidos em mercadoria. Além da rigidez locacional, a valorização de recursos minerais está sujeita a determinações que não se restringem às supostas curvas de oferta e demanda: há um conjunto de fatores de ordem política que têm peso na estruturação e que devem ser incorporados às análises. As indústrias de transformação de bens primários em produtos semi-acabados não têm a mesma rigidez locacional e tendem a se situar em lugares ou em aglomerações específicas, os bens minerais transformados industrialmente são em seguida encaminhados para consumidores de outras aglomerações.

As cidades e os municípios conectados, direta ou indiretamente, aos eixos formados pelas vias de transporte (rios ou estradas, rodovias ou ferrovias) que ligam as minas às áreas de exportação lidam com fluxos de diversas ordens. Tem relevância na (re)organização territorial a ligação de áreas de extração de recursos minerais aos centros urbanos - já existentes ou em formação - de funções variadas, entre as quais a portuária, que favorece a localização de indústrias de transformação mineral voltadas para a exportação. (Re)estruturam-se, assim, sistemas territoriais necessários à operação de certas empresas, que encontram nos fatores internos (custos de produção) e externos (vantagens competitivas, instituições, hierarquização do sistema mundial) limites para as tentativas estratégicas de modernização ligadas à verticalização da indústria de bens de origem mineral.

As vantagens competitivas induzidas pelas relações horizontais e verticais podem resultar na formação de distritos industriais importantes, principalmente na cidade-porto. Esses distritos industriais reúnem particularmente indústrias que compartilhariam os riscos sistêmicos de instalação, de funcionamento e de busca de inovações constantes. Ressalte-se, porém, que um dos efeitos espaciais da industrialização com base na mineração nas formações sociais de economia basicamente extrativa tem sido o parco desenvolvimento dos distritos industriais, nesses moldes. Isso também fragiliza a criação de aglomerações urbanas capazes de alterar significativamente as redes urbanas e industriais regionais.

\section{Mineração e desenvolvimento: indicando interações}

A aplicação de modelos, baseados nas noções de equilíbrio, de retornos marginais, de custos de transferências, etc., é heuristicamente 
ineficaz para apreender a interação entre mineração industrial e desenvolvimento regional, pois essa abordagem teórica localiza o seu foco analítico em manifestações que expressam a aparência de fenômenos, ou seja, deixa-se levar pelo fetichismo da mercadoria, não investigando as relações a ele subjacentes. Tal atitude teórica produz um bloqueio que inviabiliza a apreensão das relações sociais existentes, das relações que os produtores estabelecem entre si e das que se estabelecem entre eles e a natureza. O fetichismo da mercadoria não oculta apenas relações sociais, apresentando-as unicamente como relações entre coisas; também oculta implicações sociais derivadas de determinações naturais que marcam a produção de mercadorias.

Já o problema central das abordagens inspiradas na termodinâmica clássica é a incapacidade de incorporarem aos seus esquemas analíticos a noção de que a dissipação energético-material, vinculada à produção social, pode não ter, necessariamente, um caráter socialmente negativo. Ou seja, a exploração e, por conseguinte, a dispersão do minério que está contido em uma mina podem contribuir ou não para que a região na qual se localiza a mina edifique estruturas que favoreçam o desenvolvimento social.

Assim, parece que padrões de análise das implicações sociais da mineração, com maior poder heurístico, capazes, portanto, de aproximar analiticamente produtores, escalas (local, regional e global), dinâmicas socioeconômicas e espaço físico, devem vincular-se à análise da produção mercantil, pois a mercadoria é o que há de mais geral na sociedade moderna. Há de se levar particularmente em conta que os minérios, como toda mercadoria, ao congregar contraditória e simultaneamente valor de uso e valor de troca, têm vinculações indissociáveis com as propriedades da matéria, e o valor de troca é indissociável dos processos sociais de âmbito local, regional e global. Como valor de uso, os minérios têm vinculações diretas com as propriedades físicas e químicas da mercadoria. O tratamento adequado dessa questão permitiria a incorporação, em termos analíticos, das características da matéria nas determinações que servem de parâmetro à produção mercantil.

Por outro lado, analisar a valorização de recursos minerais no contexto da produção mercantil capitalista, tratada como totalidade, permite também ligar esse processo a dinâmicas sistêmicas, que levam a uma crescente ampliação do circuito de reprodução do capital e que têm efeitos não só sociais como também ambientais. Por conseguinte, a não incorporação desses aspectos à espacialização da mercantilização de recursos minerais resulta em uma lacuna analítica, pois a crescente valorização do valor em escala planetária requer novas estruturas aptas a valorizar recursos de origem mineral, o que implica igualmente a crescente e irrevogável dispersão energética e material. 
A lógica da produção da economia moderna, além de provocar uma permanente ampliação da produtividade do trabalho, estimula a busca de novas fontes de matéria e energia dotadas de baixa entropia e sua inclusão nos circuitos mundiais de valorização do capital, expressando uma dinâmica sistêmica, cuja reprodução requer crescente e contínuo acesso a fontes de matéria e energia, entre as quais os minérios. Trata-se de uma dinâmica de aceleração que tem sua mola propulsora nas determinações da produção mercantil, que compromete a integridade funcional de ecossistemas e a coerência de estruturas sociais.

Por conseguinte, a valorização de produtos minerais envolve as dimensões ambiental e social, cada uma delas uma totalidade lógica dotada de padrão estruturador, de tempo próprio (Brüseke, 1996), enfim, de determinações singulares, o que, entretanto, não as cinde em termos concretos. Nesse aspecto, as repercussões de determinações de caráter ambiental são incorporadas ao esquema analítico, pois as repercussões dessas determinações sobre a dimensão social são captadas, em termos analíticos, pelas especificidades biofísicas que repercutem diretamente sobre o valor de uso de cada mercadoria.

Já a articulação entre determinações sociais de caráter sistêmico com os diferenciados espaços de uma economia-mundo hierarquizada dá-se por intermédio de formações sociais e econômicas particulares. A constituição dessas formações sociais tem como parâmetros estruturas que sintetizam distintos modos de interação entre competências técnicas; características históricas, sociais, culturais, políticas; espacialidades e potencialidades da natureza. Da existência de formações sociais particulares decorrem diferenciadas interferências no espaço físico e nas determinações sociais que estabelecem parâmetros à reprodução do sistema capitalista, com implicações diretas no processo de desenvolvimento tanto no presente como também nos limites futuros e mais gerais de cada uma delas em particular.

Assim, no esforço de apreender as interações entre grande mineração industrial e desenvolvimento, com base na análise da valorização de recursos minerais, que necessariamente envolve degradação energético material, só faz sentido recorrer a abordagens que possibilitem captar a expressão material e energética dessas articulações se se levar em conta que, assim como os fluxos monetários representam a aparência das relações subjacentes, os fluxos energéticos e materiais representam manifestações de superfície de uma vasta complexidade de interações entre totalidades lógicas distintas. Por isso, é necessário identificar estruturas, espacialidades, relações e determinações, tanto sociais quanto naturais, que se configuram como o conteúdo essencial subjacente às formas de aparência manifestas tanto por fluxos monetários, quanto pela degradação energética e material. 


\section{REFERÊNCIAS}

ALTVATER, Elmar. O preço da riqueza. São Paulo: Universidade Paulista, 1995.

AMIN, Samir. Accumulation on a world scale: a critique of the theory of underdevelopment. New York: Monthly Review Press, 1974.

ARGHIRI, Emmanuel. Unequal exchange: a study of the imperialism of trade. New York: Monthly Review Press, 1972.

AYRES, Robert; KNEESE, Allen V. Production , consumption, and externalities. The American Economic Review, Pittsburgh, v. 59(3), pages 282-297, June 1969.

BARHAM, Bradford; BUNKER, Stephen G.; O'HEARN, Denis. Raw material industries in resource-rich regions. In: BARHAM, Bradford; BUNKER, Stephen G.; O'HEARN, Denis (Ed.). States, firms, and raw materials: the world economy and ecology of aluminum. Madison: University of Wisconsin Press, 1994.

BENKO, G. Economia, espaço e globalização na aurora do século XXI. São Paulo: Hucitec, 1996.

BRÜSEKE, Franz J. A lógica da decadência: desestruturação sócioeconômica, o problema da anomia e o desenvolvimento sustentável. Belém: CEJUP, 1996.

BRAUDEL, Fernand. On History. Chicago: University of Chicago Press. 1982. 236 p.

BUNKER, Stephen G. Raw material and the global economy: oversights and distortions in industrial ecology. Society \& Natural Resources, Philadelphia, n. 9, p. 419 -429, 1996.

BUNKER, Stephen G. Flimsy, joint ventures in fragile environments. In: BARHAM, Bradford; BUNKER, Stephen G.; O'HEARN, Denis (Ed.). States, firms, and raw materials: the world economy and ecology of aluminum. Madison: University of Wisconsin Press, 1994a. p. 261-296.

BUNKER, Stephen G. The political economy and ecology of raw material extraction and trade. In: SOCOLOW, R.; ANDREWS, C.; BERKOUT, F. et al (Ed.). Industrial ecology and global change. New York: Cambridge University Press, 1994b. p. 437-450. 
BUNKER, Stephen G. Underdeveloping the Amazon: extraction, unequal exchange, and the failure of the modern state. Chicago and London: University of Chicago, 1985.

CARDOSO, Fernando Henrique; FALETTO, Enzo. Dependency and development in Latin America. Berkeley, CA: University of California Press, 1979.

CARDOSO, Fernando Henrique; FALETTO, Enzo. Dependência e desenvolvimento na América Latina. Rio de Janeiro: Zahar, 1970.

CHILCOTE, R. Teorias de política comparativa: a busca de um paradigma reconsiderado. Petrópolis: Vozes, 1998.

COASE, R. H. The firm, the market, and the law: the problem of social cost. Chicago, London: University of Chicago Press, 1988.

COELHO, M. C. N. Política e gestão ambiental (des)integrada dos recursos minerais na Amazônia Oriental. In: COELHO, Maria Célia Nunes; SIMONIAN, Lígia; FENZL, Norbert (Org.). Estado e políticas públicas na Amazônia: gestão de recursos naturais. Belém: CEJUP/ NAEA/UFPA, 2000. p.117- 170.

DALY, Herman. Introducción a la economía en estado estacionario. In: DALY, Herman. Economía, ecología y ética: ensayos hacia una economía en estado estacionario. México: Fondo de Cultura Económica, 1989a. p. 11-43.

DALY, Herman. La economía en estado estacionario: hacia una economía del equilibrio biofísico y el crecimiento moral. In: DALY, Herman. Economía, ecología y ética: ensayos hacia una economía en estado estacionario. México: Fondo de Cultura Económica, 1989b. p. 334-367.

DOSI et al. Technical change and economic theory. London: Pinter Publishers, 1988.

FEMIA, Aldo. Input-output analysis of material flows: an application to the German economic system for year 1990. Milano: Università degli Studi di Ancona, Dipartimento di Economia, 1996.

FRANK, A. G. The development of underdevelopment. Boston, MA: New England Free Press, 1966. 
FREEMAN, C. The economics of technical change. Cambridge Journal of Economics, Oxford, v. 18, p. 463-514, 1994.

GEORGESGU-ROEGEN, Nicholas. La ley de la Entropía y el problema económico. In: DALY, Herman (Org.) E. Economía, ecología y ética: ensayos hacia una economía en estado estacionario. México: Fondo de Cultura Económica, 1989. p. 61-72.

GEORGESGU-ROEGEN, Nicholas. The entropy law and the economic process. 4. ed. Cambridge, London: Harvard University Press, 1971.

GONZALEZ-VIGIL, F. New technologies, industrial restructuring and changing patterns of metal consumption. Raw Materials Report, Stockholm, v. 3, n. 3, p.11-31, 1984.

HARVEY, D. Justice, nature and the geography of difference. Oxford: Blackwell, 1996.

HIRSCHMAN, Albert O. Estratégia do desenvolvimento econômico. Rio de Janeiro: Fundo de Cultura, 1961.

HOBSBAWM, Eric. Sobre la historia Barcelona: Crítica, 1998; Tradução Jordi Beltrán. 298 p.

HOTELLiNG, H. Edge worth's Taxation Paradox and the Nature of Demand and Supply Functions. Journal of Political Economy, Chicago, n. 40, p. 577-616, 1932.

INNIS, H. A. Essays in Canadian economic history. Mary Q. Innis (ed.). Toronto: University of Toronto Press, 1956.

MÄLER, K. Environmental Economics: a theoretical inquiry. Baltimore: John Hopkins University Press, 1974.

MARINI, R. M. Subdesarrollo y revolución. México: Siglo Veintiuno Editores, 1969.

MARTIN, Jean-Marie. A Economia Mundial da Energia. São Paulo: UNESP, 1992.

MARX, Karl. O capital: crítica da economia política. 13 ed. Rio de Janeiro: Bertrand Brasil, 1989.

MYRDAL, G. Economic theory and under-developed regions. London: Duckworth London, 1957.

42 
MONTEIRO, M. A. Mineração e Metalurgia na Amazônia: contribuição à crítica da ecologia política à valorização de recursos minerais da região. 2001. Tese (Doutorado em Desenvolvimento Sustentável do Trópico Úmido) Belém: Universidade Federal do Pará, 2002.

NAKICENOVIC, Nebojsa. Freeing energy from carbon. In: AUSUBEL, Jesse; LANGFORD, H. DALE (Ed.). Technological trajectories and the human environment. Washington, DC: National Academy of Sciences, 1997. p. 74-88.

NELSON, R.R.; WINTER S.G. An Evolutionary Theory of Economic Change, Cambridge, Mass: Harvard University Press, 1982

ODUM, H. T. Environmental Accounting: EMERGY and environmental decision making. New York: Wiley-Interscience, 1995. 384 p.

PEARCE, David; BARBIER, Edward B.; MARKANDYA, Anil. Sustainable development: economics and environment in the Third World. London: James G James/Earthscan, 1991. 228 p.

PIGOU, A. C. Economics of welfare. London: Macmillam, 1932.

PRIGOGINE, Ilya. O fim das certezas: tempo caos e as leis da natureza. São Paulo: UNESP, 1996.

PRIGOGINE, Ilya; STENGERS, I. A nova aliança: metamorfose da ciência. Brasília: UnB, 1984.

PRIGOGINE, I.; STENGERS, I.. Entre o Tempo e a Eternidade. São Paulo: Companhia das Letras, 1992.

REDCLIFT, Michael. Sustainable development: exploring the contradictions. London and New York: Routledge, 1987.

REDCLIFT, Michael. Development and environmental crisis: red or green alternative? London and New York: Methuen, 1984.

SANTOS, T. dos. Imperialismo y dependência. México: Ed. Era, 1978.

SCHIPPER, Lee. Life-styles and the environment: the case of energy. In: AUSUBEL, Jesse H.; LANGFORD, H. DALE (Ed.). Technological trajectories and the human environment. Washington, DC: National Academy of Sciences, 1997. p. 89-109.

SOJA, Eward W. Geografias pós-modernas: a reafirmação do espaço na teoria social. Rio de Janeiro: Jorge Zahar, 1993. 
TIBBS, H. B. C. Industrial ecology: an environmental agenda for industry. Whole Earth Review, San Rafael, n. 4, p. 4-19. 1992.

WALLERSTEIN, Immanuel. The Modern World-System: Capitalist Agriculture and the Origins of the European World-Economy in the Sixteenth Century. New York: Academic Press, 1974.

WEBER, A. Theory of location of industries, 2nd edition. Chicago: University of Chicago Press, 1957.

YAPA, Lakshman. Reply: why discourse matters, materially. Annals of the Association of American Geographers, Washington, v. 87, n. 4, p. 717-722, 1980. 